Meta

Journal des traducteurs

Translators' Journal

\title{
Authenticity and Quality of Translation
}

\section{Peter Gawn}

Volume 33, numéro 3, septembre 1988

URI : https://id.erudit.org/iderudit/002831ar

DOI : https://doi.org/10.7202/002831ar

Aller au sommaire du numéro

Éditeur(s)

Les Presses de l'Université de Montréal

ISSN

0026-0452 (imprimé)

1492-1421 (numérique)

Découvrir la revue

Citer cette note

Gawn, P. (1988). Authenticity and Quality of Translation. Meta, 33(3), 456-460.

https://doi.org/10.7202/002831ar

Ce document est protégé par la loi sur le droit d'auteur. L'utilisation des services d'Érudit (y compris la reproduction) est assujettie à sa politique d'utilisation que vous pouvez consulter en ligne.

https://apropos.erudit.org/fr/usagers/politique-dutilisation/
Cet article est diffusé et préservé par Érudit.

Érudit est un consortium interuniversitaire sans but lucratif composé de l’Université de Montréal, l'Université Laval et l'Université du Québec à Montréal. Il a pour mission la promotion et la valorisation de la recherche. https://www.erudit.org/fr/ 


\section{BLOC-NOTES}

\section{AUTHENTICITY AND QUALITY OF TRANSLATION}

Public administrations in Canada have always recognized the requirement for a mechanism for communication with individuals or groups who do not speak the language of the principal administrators. The mechanism adopted at the beginning of Canada's recorded history was the employment of a third party who knew the languages of the administrator and the administratee sufficiently well to act as a communication bridge. This often rudimentary and primitive bridge is still, 400 years after Jacque Cartier kidnapped two Iroquois from Stadacona and made them his interpreters, the main link between cultures and languages in the federal government's dealings with an important segment of the Canadian mosaic.

It is a well-documented fact that the federal government still works primarily in English. Communication with French-speaking Canadians passes across the translation bridge, in a one-way traffic that many deplore

In his report to Parliament for 1984, the Cornmissioner of Official Languages comments :

Francophone viewpoints that are transmitted to government in English are no longer really Francophone viewpoints, and a government that listens to and talks to a quarter of its constituents via translation and interpretation cannot claim to be in touch ${ }^{1}$.

My point in quoting this remark is not to discuss it validity but to illustrate the reality that the federal government works largely in English, using the successors of Cartier's Iroquois "volunteers" to convey its messages. Mr. D'Iberville Fortier also notes

that in 1983-1984 about 90 per cent of texts destined for internal use (in the federal government) originated in English ${ }^{2}$.

The reality is evident.

By law, namely the Official Languages Act 1968-1969, the government must issue its public do- cuments in both French and English. Given the situation alluded to in the two quotations from the Commissioner of Official Languages it is obvious that nearly all the rules, orders, regulations, by laws and proclamations referred to in Section 4 of the Official Languages Act are written in English and then put into French.

This procedure is not without giving offence. Mr. Léo Létourneau, President of the Fédération des francophones hors Québec, in a vigorous presentation to a meeting of government officers responsible for implementing the Official Languages programme in government departments and agencies, criticized the practice of communicating with francophones by means of "the translation of texts conceived by and for anglophones... however good the translations might be" ${ }^{\prime 3}$. He advocated instead the conception and preparation of French versions by francophones coming from the same milieu as the eventual readers of the documents in question. Or, to put it another way, he situated the question on the cultural rather than on the more straightforward linguistic plane, thus causing one to reflect on the possibility or impossibility of effecting cross-cultural transfers.

Viewed in this context, the task that society confers on the translator becomes quite awesome. We expect in fact that the translator will take a message created by, say, a prairie-educated economist writing with a Bay Street financier in mind, and recast it as if it came from a graduate of the Hautes études commerciales addressing an entrepreneur from the rue Saint-Jacques. Or, do we in fact expect this ? Are we not more reassured when the French text is no more than a mirror image of the English original, a faithful if pedantic interpretation of a musical score composed in the English idiom?

What I am talking about here is authenticity, or one aspect of authenticity. Does the translation produce on its reader the same effect as the original was designed to elicit from the original reader? This is a topic of infinite interest and considerable importance, but one that I am not prepared to deal with here. Indeed, since I am not a theoretician, I doubt if I am equipped to deal with it at all.

There is however a more immediate aspect of authenticity, namely the equal value in law of two or more versions of a text in different languages. It is in- 


\section{A selective case study}

The abovementioned comments may be illustrated by considering a few examples taken from the vocabulary. All opinions expressed following the translations are strictly our own.

- action concertée : concerted action : acção concertada p. 9 : This is a typical example of trendy Frenchspeak that splashes over into other languages wherever there is sufficient contact. The English and Portuguese calques certainly do not have the administrative clout of the French original.

- acte contesté : act concerned p. 9 : This example is striking due to the difference in semantic content. While the law may be declare to be one, Catholic and universal in all European languages, this phrase does not comply thereto.

- biens immobiliers et mobiliers : movable and immovable property p. 17 : It should be most interesting to know English barristers and solicitors react to this abracadabra translation. We know it will produce legal effects when applied to national legislations. Now, what kind of effects in which countries?

aggravation du secret : upgrading of the classification : agravemento do segredo p. $16:$ Here is an curious example of transparency or lack thereof. Does the English reader come away from his or her persual with the same impression as a Portuguese reader?

aménagement du prix de transport : making of rates p. 19 : There is obviously more content in French.

a l'amiable : by amicable agreement p. $20:$ The English may concede that the French are quite friendly, however this matter has nothing to do in French legalese with friendship.

pièces et documents à l'appui : papers and documents in support p. 26 : What happened to "vouchers" in English?

avis : opinion, notice, assent p. 36 : The French versions has one word denoting three realities. The English version specifies each separate reality. In which language does a researcher have the best chances of finding information?

- avoir pour but de : (no entry) : ter por fim p. 45 : This interesting example illustrates how nontechnical speech can on occasions be promoted to shaky terminological rank in one language and yet go wholly unnoticed elsewhere. Comparative theoretical terminology - which often ducks rhetorical usages - as yet to explain this one adequately.

domicile : home : domicilio p. 51 : In the European Communities "Home, Sweet, Home" looks to be a lexical quagmire. Legal terminology is hindered by the diverse national definitions of domicile and residence, now we shall have to reckon with "home".

Despite some of our previously harsh comments, the mere existence of this vocabulary is definitely to the honour of all those who contributed to compiling it. The difficulties should only serve to underscore the need in future for down-to-earth research in presenting useful aids to translators and writers. In closing, I offer my congratulations to the authors for coming this far and my hope that their next vocabulary will incorporate additional practical linguistic tools.

WALLACE SCHWAB 
teresting to note that this aspect of authenticity posed a problem to the drafters of the Official Languages Act, and presumably to the legislators as well. They accepted as a given that the two versions of an enactment may differ. They accepted, by implication, that perfect translation, the cross-cultural transfer, or even the simpler linguistic transfer I mentioned earlier, may not always be achieved. In this connection, Section 8 (i) of the Official Languages Act is both concise and precise. It reads "In construing an enactment, both its versions in the Official Languages are equally authentic". Enactment is defined as any Act of the Parliament of Canada, or any rule, order, regulation, by-law or proclamation to be published in the official gazette of Canada. The following subsection of the Act indicates, however, in four paragraphs, how subsection (i) is to be applied "where it is alleged or appears that the two versions of the enactment differ in their meaning". In such a case, the subsection concludes that if the difference is not due to divergencies in the legal systems or institutions, then "preference shall be given to the version thereof that, according to the true spirit, intent and meaning of the enactment, best ensures the attainment of its objects". This resolution of the problem requires, incidentally, an advanced knowledge of both languages on the part of the person or persons attempting to decide which of the two versions of an enactment best reflects its spirit, intent and meaning.

Legislation, and most subsidiary legislation and so on of the type referred to in the Official Languages Act, is located at the high end of the translation continuum. By translation continuum I am referring to the extent to which the version of a text in a target language is developed using the skills and contribution of people other than translators. In other words, at the low end of the continuum, the translator is given entire responsibility for producing the target-language text alone, whereas, at the high end, both versions are prepared more-or-less simultaneously by subject specialists or writers, possibly without any input from a translator. Such is generally the case for the acts of the Parliament of $\mathrm{Ca}$ nada, but not for all subsidiary legislation. Indeed, since government regulations are prepared in the departments responsible for whatever activity is covered by the regulations, and because, as we have seen, of the overwhelming proportion of original texts prepared in English, not only are many of the subjectspecialists, legal advisors and drafters unable to produce texts in French, but they are also unable to read them in French. The part played by the transiator thus becomes preponderant. One could almost formulate $A L A W$ : the value of a translator is in inverse proportion to the client's degree of bilingualism or target-language knowledge.

However that may be, and without intending in any way to denigrate in the following remarks the competence and conscientiousness of translators, I nevertheless seriously question whether we can say that the two versions of a document are of equal value when one version is drafted by a subject specia- list, possibly reviewed by other subject specialists, and sometimes revised by senior officials or professional writers, while the other version is produced, often in very short time, by a translator, possibly working alone, and with limited access to subject specialists capable of discussing the subject matter in the target language. How many times do we not see the same pattern : a document is developed in English, during weeks, months or even years; is the subject of discussion and consultation ; is put into final form - and then has to be translated almost overnight. And when one thinks of the many texts dealing with topics for which there may not yet be any accepted terminology in French, or discussing concepts or institutions that have no direct parallel in francophone culture, or describing advances in technology or thought that are ahead of work done so far in French-speaking countries, one could be tempted to formulate $A S E C O N D L A W$, namely : the possibility of a successful translation is proportional to the parallelism of the two cultures involved.

Possibly I can illustrate the situation I have attempted to describe by an example which, although somewhat extreme, is nevertheless not atypical.

There was a requirement to translate in very little time, with an ineluctable deadline, a substantial study in the field of law that had been prepared by a working group of English speaking specialists. For various reasons mainly related to the deadline, the text was assigned to a single translator, a free-lance, who, working alone, wrote the French version in a fraction of the time that had been devoted to writing the original. No French speaking specialists were available for consultation, and the translator had leisure for only minimal research. I am sure that all of you with translation experience could come up with similar if less flagrant examples of this type of Mission Impossible. The point I want to make is that, short of a miracle, it is unlikely that a French version produced in such circumstances can measure up to the quality of the English original. It would indeed be unreasonable to expect it to do so. It is also unreasonable to pretend that both versions of such a text can be considered authentic : at best, the French version can only be a mirror-image of the English, hopefully an undistorted image and not the grotesque kind of image traditionally provided by fair-ground mirrors.

There is another aspect of authenticity, and one that will lead me to my second major concern, the quality of translation. This aspect of authenticity has to do with the finished translation as an independent piece of writing, as a literary artifact. Does it ring true? Does it read the way a French author, working independently of a source document in English, would have written it? Does the author of the original English text recognize himself or herself in the French translation? Does it describe the subject content in the same terms that a French specialist 
writer would have used ? Does it respect the cultural norms of the target-language culture?

I do not think many of you will disagree if I answer these questions by saying "Not all the time".

Let me digress a minute, and try to evaluate the extent of the cultural, literary and language impact that the federal government's translations have on francophone culture. As we have seen, most translation in the federal government is done from English into French. The total volume runs at more than 200 million words a year. This is more-or-less equivalent to half-a-dozen fair-sized books every working day. Now of course, not all these works are best-sellers. Indeed, many of the texts are addressed to small readerships. But the habits of writing, the vocabulary, the turns of phrase, the style, may well be picked up by the reader, and reappear in the reader's own writing or speech. And if, in the main, these translations lack the authenticity of original writing, then their cumulative effect on the French language in Canada is significant.

What are some of the factors that lessen the possibility of producing a translation in French that will meet the test of authenticity? The list is not overly long, and the factors are all well known and obvious. We have mentioned some of them already. The main factors can be placed in two categories : those that are or that should be the responsibility of the client, the person asking for the translation to be done, and those that are the responsibility of the translator, or of the manager of the translation service.

In the first category, client problems, I place the time available for translation, the degree of access to client-controlled resources, the quality of source-language texts, the isolation of the translation act, and the level of importance that the client attaches to the translation.

In the second category, translator problems, I identify the inexperience, inability and incompetence of the translator, poor work organization, inadequate support systems, and too-ready compliance with inappropriate client demands.

I want to say a few words about each of these factors. But before I do so I want to make one general comment. In my view there is still a fundamental misconception about the purpose of, and the responsibility for, non literary translation in Canada. It is this misconception that contributes to the perpetuation of several of the factors $I$ just listed, and thus contributes also to the continuation of impaired authenticity. The misconception can be simply stated : namely, that translation is the responsibility of the translator. And by extension, in the context of the anglophone preponderance I talked about at the beginning of this paper, the misconception becomes : French is the responsibility of the translator. Furthermore, by extension on the part of the translator and the client, the misconception arises that the role of the client is to write an English source text, and the role of the translator is to mirror it in French.
If this is indeed a misconception, what should the correct conception be ? Simply, that it is the role and the responsibility of the client to produce a document that is authentic in both French and English, and that it is the role and the responsibility of the translator to help him do so. In this context, particularly in an administration like the federal government, the translator can then be better described as a specialist in intertextual transfer, to borrow a description proposed by the Leipzig school, and no longer viewed as the privileged custodian or guardian of the French language, or the sole authority on interlingual transfer.

Once it is clear that the client has prime responsibility for producing both versions of a bilingual text, then many of the factors affecting quality can be alleviated, and the probability of achieving a good and authentic translation can be enhanced. In fact, we could advance $A T H I R D L A W$ : the quality of a translation is proportional to the degree of the client's commitment to bilingualism. And, as a corollary, one can assume that a fully collaborative attitude between client and translator, whereby the former associates himself with the translator's work and does not just sit back and wait for a product to be delivered for scrutiny and, sometimes adverse, comment, would go a long way to eliminating the factors hindering quality in translation.

Let me now review those factors. First is the time available for translation. Curiously, and contrary to mutually accepted practice in other professional or even non-professional service activities, it is often the client who establishes or attempts to establish the time available for translation. Typically, the translator's reaction is to decide how the preestablished deadline can be met, or if it can be met at all, rather than to challenge the validity of the deadline. The assumption on the client's part appears to be that translation is a logistical problem, or a question of numerical resources rather than a project requiring research, planning, coordination, production-and-quality control, and so on, to say nothing of reconciling conflicting priority tasks from the same client group. The translator's work is viewed as being on the artisan level where production is a function of effort, although the client may well consider the production of his original text as an intellectual or industrial-type undertaking with all that that implies for the conception, design and preparation of the final product.

We all know of course that over the years translators have consistently made heroic efforts to satisfy client-imposed deadlines. By doing so they have created levels of expectation that cannot now be easily denied. And wherever possible, and when the deadlines are justified, translators will and should continue to meet the client's requirements. But, to do so often calls for a performance on the translator's part at the level, to borrow a musical image, of the virtuoso. The virtuoso can turn in a polished performance on short or no notice because of his advanced skill, his years of practice, his knowledge of the mu- 
sic, his mastery of his art. But even the virtuoso would have difficulty playing on sight a musical score he had not studied, particularly one written by a composer whose previous work he does not know, and in an idiom which is unfamiliar to him.

The analogy between the musician and the translator is a useful one. Each works from a written text or score, each needs to study the piece in question and previous work from the same hand, each needs to know the idiom, needs to see how others have resolved comparable difficulties, each, in short, needs time to research and practice before performing. The translator's client expects a virtuoso performance every time : the musician's client expects the musician to set the parameters for his performance.

Clear identification of the parameters for the translator's performance are lacking. The time available for translation is usually viewed as a multiple of pages or words and average speed. The profession could benefit from an analysis of the steps involved in translation, and a statement of those steps that would enable the client to appreciate the importance of planning translation time properly in the overall production schedule for the bilingual document. Most of the steps involved in translation are mentioned in this paper : I encourage active professionals to develop and build on them.

The second quality-affecting factor I listed was access to client-controlled resources. I have in mind reference material, resource people, hands-on contact with whatever is being discussed in the document to be translated, access to target-language subject or writing specialists, discussion with known or possible users of the translation, and so on. There is no need to dwell on this factor since its importance is so obvious, except to note, also, that it is too often neglected.

Thirdly, I identified the quality of sourcelanguage texts. Clearly this is the client's responsibility. It is less clear to what extent the translator should refuse or return for re-write a document whose obscurity or lack of clarity defies or impairs translation. The subjectivity involved in passing a judgement on readability has sufficed to confuse this issue, and the tendency has been to depreciate the translator's reading skill. The advent of computeraids to writing, including readability evaluation, could help convince clients and authors that their message is not coming across. The Language Bureau of the Northwest Territories will not accept for translation into Indian and Inuit languages a document rated by computer analysis as being insufficiently clear. Less sophisticated but quite reliable and simple methods for estimating the level of education required to understand a text exist. I suggest that the professional associations evaluate these techniques and develop an instrument for translators to use in their discussions with obfuscation-loving clients. In any event, however, it is reasonable to expect a client to accept as valid the opinion of a professional translator that the original text could be improved since the rigorous analysis that translation involves always identifies the weaknesses of the original.

The fourth client-related factor is the isolation of the translation act. I have touched on several facets of this already. I have in mind the situation, fairly typical, in which the client finishes his text and sends it for translation in the expectation that the translator will return the finished translation in short order and without any interaction between translator and client. A sort of black-boxism, whereby the original is fed into the system, the system does its work, and the translation comes out, untouched by human hands. I shall not spend any more time on this factor, except to deplore it.

Finally for the client-related problems, is the importance the client attaches to having the translation, and to having a good translation. Again, I think what I have already said in this paper suffices. If the client wants a good translation, then he will collaborate with the translator, and will work with him to produce it.

What about the translator-related problems? I mentioned four. The first was the inexperience, inability or incompetence of the translator. Not every practicing translator is a virtuoso. Some are debutants, some are workmanlike, some have not kept up with the pace of change, some should be finding their niche elsewhere than in such an exacting profession. Translating is not for every person who knows both languages. Like it or not, professional associations and employers must ensure that only those who can translate are recognized by the first and engaged by the second. Much work remains to be done in identifying the skills, ability, and knowledge required of a translator, in developing tests for assessing potential, in improving objective methods for evaluating the quality of a translator's work, in setting levels of tolerance, in demarcating the difficulty or complexity of texts and the corresponding degrees of competence they call for, and in applying all these diagnostic and measurement tools in a rational and constructive way. In the end, however, it is up to the individual practitioner to set his limits, identify his areas of competence and organize his professional life accordingly.

The organization of work is my second translator-related factor affecting quality. For years, the translator was a soloist. Today, he is increasingly part of a team, if not of an orchestra, although when as sometimes happens, a text is divided up amongst a group of translators, he becomes a performer in a quartet, octet or whatever. I spoke earlier about the desirability of analyzing the steps in translation. Once this analysis is done, the work should be organized accordingly - check for existing translation, evaluation of translatability, pre-editing and preparation of text, location of models and reference material, provision of terminology, use of support systems, verification through on-line quality control, monitoring of process to provide feedback for improved work organization, and so on. Translation is an intellectual process, but the actual conversion from 